\title{
LYMPHATIC FILARIASIS: EPIDEMIOLOGICAL ANALYSIS OF THE SITUATION IN SALYANTAR VDC OF DHADING DISTRICT, NEPAL
}

\author{
R. Byanju ${ }^{1}$ and R. Gupta ${ }^{2}$
}

\begin{abstract}
A cross sectional survey was carried out by taking 516 mid night blood samples from 206 households in 1,2 and 3 wards of Salyantar village development committee of Dhading district, Nepal with the objective to analyze the epidemiological situation of lymphatic filariasis. The main aim of the study was to provide the data essential for the planning, implementation and evaluation of the services to the prevention, control and treatment of lymphatic filariasis.
\end{abstract}

Questionnaire survey was conducted for the collection of information of the respondents. Blood samples were collected by means of ear-lobe prick method. Microscopical examination of the collected blood samples revealed 117 positive cases i.e. $22.67 \%$. Males $(24.54 \%)$ were found to be infected more than females $(21.28 \%)$ in the ration of $1.2: 1$. The highest distribution of microfilarial parasites was in the age group $>70$ years $(36.36 \%)$ while the least was in the age group $\leq 10$ years $(12.37 \%)$. The infected youngest person was 4 years old boy and the oldest was 85 years old man. Endemicity rate and crude disease rate was reported to be $44.76 \%$ and $22.09 \%$ respectively. Illiteracy, lack of awareness about the disease, poor sanitation, carelessness in using bed-nets and health were identified as the major risk factors for filariasis.

Key Words: Iymphodema, elephantiasis, microfilaria, Wuchereria bancrofti, hydrocoele, crude disease rate

\section{INTRODUCTION}

Lymphatic filariasis (LF), also known as elephantiasis is a parasitic disease caused by filarial nematode, Wuchereria bancrofti, the infection of which causes the inflammation of lymphatic system resulting hydrocoele of scrotum, breast enlargement, lymphodema of limbs, enlargement of penis, swollen clitoris and vulva. Wuchereria bancrofti is the only species reported from Nepal among all other filarial worms and it is the main cause of lymphatic filariasis in Nepal (Thakur 2000). Lymphatic filariasis is well established in tropics and sub tropics, causing major socio- economic burden globally. It is endemic in 90 countries and more than 1.1 billion people in the tropical and sub-tropical regions of the world are infected, of these $90 \%$ are caused by Wuchereria bancrofti and $10 \%$ by Brugia malayi, limited to Asia and some parts of Pacific (WHO 1997). Almost 27 million men suffer from genital disease hydrocoele, more than 15 million suffer from lymphodema or elephantiasis of limb, 83 million from lymphatic disabilities and 30 million from renal pathology (WHO 1997).

In Nepal, out of total population (approximately 23.2 million), 13.9 million (60\%) are estimated to be at risk of infection. It is endemic in different regions of Nepal. Similar studies were also carried out by Sherchand et al. (2003), Ghimire et al. (2003), Manandhar (2001), and Prad- 
han et al.(1997). The total number of filarial case, based on the annual report of $\mathrm{DoHS}, \mathrm{MoH}$ and MG, Nepal. From 2001/02 to 2004/05 the reported cases were 1183, 809, 550 and 549 respectively. The total number of filarial cases reported in Out Patient Department in the health institutions of Dhading district during the fiscal year 2004/05 was 21 in individuals (EDCD 2005).

Based on the public health importance of lymphatic filariasis, WHO has made a global call for its elimination by the year 2020 to which Nepal has also expressed its commitment and put forwarded its effort for lymphatic filariasis elimination by 2015. To action this and to prioritize the districts for the implementation of lymphatic filariasis eradication, it becomes essential to know the exact prevalence of LF for the entire country through WHO recommended standard techniques (Ghimire 2002). The prevalence rate recorded from present study in Salyantar VDC may be helpful in the implementation of the lymphatic filariasis eradication program which might be a part for the global elimination of LF as called by WHO.

The objectives of the study were to determine the filarial prevalence in relation to age, sex, occupation, education and also to find out the knowledge, attitude and practices of people towards filariasis. This study also aims to determine endemicity rate along with the symptomatic and asymptomatic cases of filariasis.

\section{STUDY AREA}

Salyantar VDC of Dhading district was selected as the present study area.

Dhading district is a hilly region located in Bagmati zone of Central Developmental Region. The altitude ranged from $488 \mathrm{~m}$ to $7409 \mathrm{~m}$ and area occupancy of 1926 sq.km (CBS 2001) with 50 VDCS 3 constituencies.

Salyantar VDC, situated in the north west of Dhading district has the total population of 7658 (male=3579 and female=4077) with 1458 no. of households and 5.25 average household size. Peoples are mostly farmers and human habitation was surrounded by poor sanitation. Almost each and every household has a large pit dug for accumulating cattle dung which is used as organic fertilizer. During monsoons, these pits get filled up with water and become one of the major sites for mosquito breeding, the main vector for the transmission of filariasis.

\section{MATERIALS AND METHODS}

\section{Study Population}

On consulting the local health personals, population with highly filariasis infected areas (ward no. 1, 2 and 3) of Salyantar VDC were chosen for the cross sectional sampling. The blood samples were collected from the family members of age above 2 years.

\section{Study Design}

Epidemiological cross sectional study was applied for the research designed in the study.

\section{Sampling Technique and Sample size}

A total of 516 blood samples collection and questionnaire filling of the same population were conducted from community of Salyantar VDC at ward no. 1, 2 and 3 of Dhading district. Questionnaires were filled during the day time and blood samples were collected at night from 10 
$\mathrm{pm}$ to $2: 30$ am when people were in relax condition in their beds.

Instrumentation: Tools used in this study were as follows:

i. Mass Orientation Programme: Mass orientation program was held before blood collection in the study area to inform all the respondents about the disease filariasis and its effects so as to motivate them for participating in the program. Everyone was informed about the purpose of the study, the time of blood sample collection and questionnaire survey.

ii. Questionnaire: The questionnaire contained name, age, sex, occupation, education, marital status, relationship with the head of the family, surrounding environment and their probable effects against disease, their current health status, and clinical symptoms of filariasis. A structured questionnaire was prepared, pre-tested and piloted before administrating in the community.

iii. Human Blood Sampling: Human blood samples were drawn by pricking the ear lobe. Three thick blood smears were prepared on a slide and dried. Later they were fixed in methanol and dehaemoglobinised using distilled water, stained with Giemsa stain and observed under different magnification of objective lenses of compound microscope. The microfilariae were identified as Wuchereria bancrofti on the basis of its characteristic features: stained sheath, discrete nuclei, empty space between the nuclei and body wall, cephalic space, absence of nuclei at tip of tail, bent tail tip underneath the body.

\section{Data Processing and Analysis}

The collected raw data were first edited to detect for error omissions and to make them accurate, uniform and well arranged, then were coded for easy classification and tabulation. Thus classified and tabulated data were analyzed by means of statistical tools and presented in table and bar diagrams.

\section{RESULTS AND DISCUSSION}

\section{General Prevalence and Sex-wise Prevalence of Microfilariaemia}

The general prevalence of microfilaria $(\mathrm{mf})$ in the blood sample was observed to be $22.67 \%$ $(117 / 516)$ of which $24.54 \%$ (54) were of males and $21.26 \%$ (63) of females. The difference of prevalence of microfilaria between male and female was found to be statistically insignificant $(\mathrm{X} 2=0.75, \mathrm{P}<0.05,3$ d.f. $)$ (Fig.1).

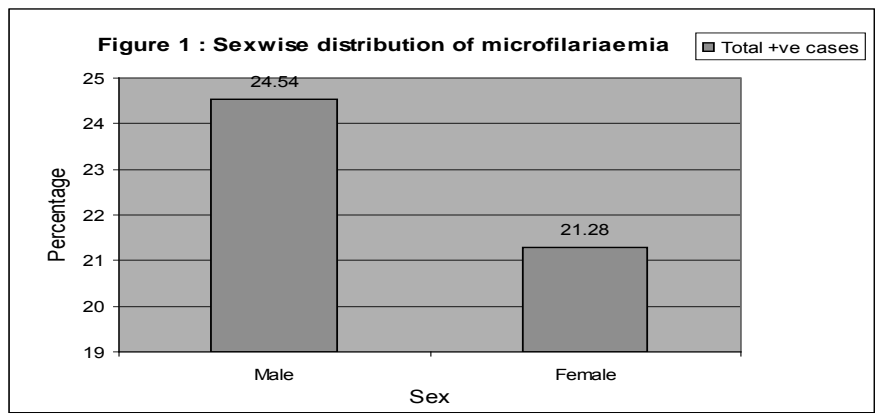




\section{Age-wise Prevalence of Microfilariaemia}

High prevalence of microfilaria was recorded in the age group $>70$ years $(36.36 \%)$ while the least in the age group $\leq 10$ years $(12.37 \%)$. Statistically, the prevalence of $\mathrm{mf}$ in different age group was found to be insignificant $(X 2=9.191, P<0.05,15$ d.f.(Fig. 2$)$.

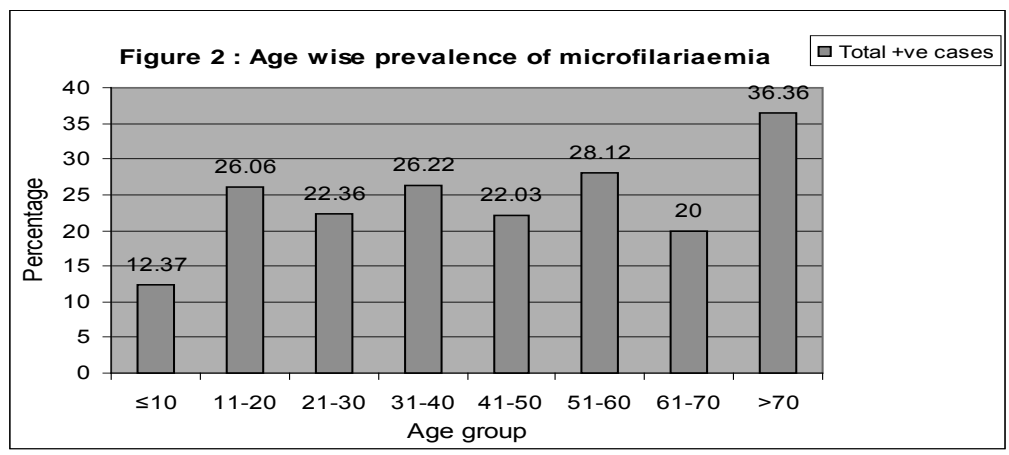

\section{Age and Sex-wise Distribution of Microfilariaemia}

Fifty percent infection rate was recorded in the age groups $61-70$ years (3/6) and $>70$ years $(3 / 6)$ of male and also in the age group between $51-60$ years $(5 / 10)$ of female while no infection was seen in the female of age group 61-70 years. Many number of samples were collected from the age group 11-20 years of both sexes, infective cases were also seen in more numbers of them i.e. $22.67 \%(17 / 75)$ in males and $28.89 \%(26 / 90)$ in females (Fig.3).

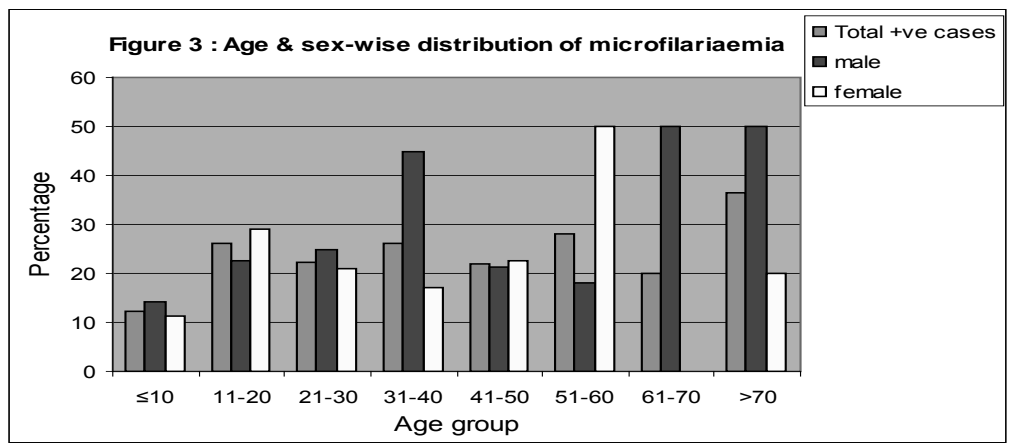

\section{Education-wise Prevalence of Microfilariaemia}

Respondents with the education up to lower secondary were highly infected with microfilaria $(31.25 \%)$ while lowest infection was observed among the respondents with primary level education $(20.13 \%)$. Statistically the education wise prevalence of $\mathrm{mf}$ was found to be insignificant $\left(X^{2}=3.579, \mathrm{P}<0.05,9\right.$ d.f. $)$ (Fig. 4). 


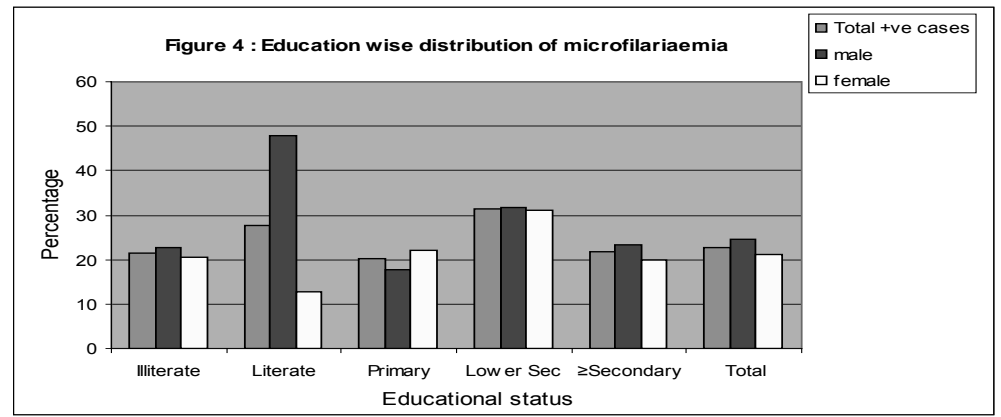

\section{Occupation-wise Distribution of Microfilaria}

Regarding occupation wise prevalence of microfilaria, maximum infection was recorded in the respondents with business as occupation (40\%) and no infection was found in children. Statistically no significant relation was found in between choose of occupation and infection. ( $X 2=12.641, P<0.05,13$ d.f. $)$ (Fig.5).

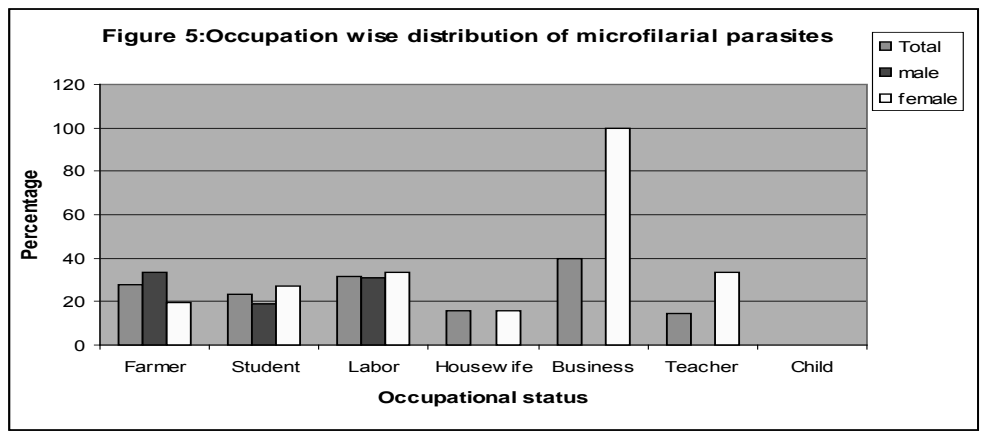

\section{Clinically Manifested Cases in the Study Population:}

Overall clinical manifestations showed the presence of 23 hydrocoele cases, 5 chylurial cases and 92 elephantiasis cases (Table 1).

Table1. Clinically manifested cases in the study area.

\begin{tabular}{|l|l|l|l|l|l|l|l|l|}
\hline Age group & \multicolumn{2}{|l|}{$\begin{array}{l}\text { Total } \\
\text { samples }\end{array}$} & \multicolumn{3}{|l|}{ Male } & \multicolumn{3}{l|}{ Female } \\
\cline { 4 - 9 } & (years) & Total & Hydrocele & Chyluria & Elephantiasis & Total & Chyluria & $\begin{array}{l}\text { Elephantiasis } \\
(\%)\end{array}$ \\
$(\%)$ & $(\%)$ & $(\%)$ & & $(\%)$ & \\
\hline$\leq 10$ & 97 & 35 & $00(00.00)$ & $0(0.00)$ & $06(17.14)$ & 62 & $0(0.00)$ & $11(17.74)$ \\
\hline $11-20$ & 165 & 75 & $02(02.67)$ & $1(1.33)$ & $11(14.66)$ & 90 & $1(1.11)$ & $09(10.00)$ \\
\hline
\end{tabular}




\begin{tabular}{|l|l|l|l|l|l|l|l|l|}
\hline $21-30$ & 76 & 28 & $00(00.00)$ & $0(0.00)$ & $09(32.14)$ & 48 & $0(0.00)$ & $06(12.50)$ \\
\hline $31-40$ & 61 & 20 & $03(15.00)$ & $0(0.00)$ & $06(30.00)$ & 41 & $1(2.44)$ & $07(17.07)$ \\
\hline $41-50$ & 59 & 28 & $12(42.86)$ & $1(3.57)$ & $05(17.86)$ & 31 & $1(3.23)$ & $09(29.03)$ \\
\hline $51-60$ & 32 & 22 & $04(18.18)$ & $0(0.00)$ & $07(31.82)$ & 10 & $0(0.00)$ & $04(40.00)$ \\
\hline $61-70$ & 15 & 06 & $01(16.66)$ & $0(0.00)$ & $02(33.33)$ & 09 & $0(0.00)$ & $00(00.00)$ \\
\hline$>70$ & 11 & 06 & $01(16.66)$ & $0(0.00)$ & $00(00.00)$ & 05 & $0(0.00)$ & $00(00.00)$ \\
\hline Total & 516 & 220 & $23(11.5)$ & $02(0.9)$ & $46(20.09)$ & 296 & $3(1.01)$ & $46(15.54)$ \\
\hline
\end{tabular}

Endemicity Rate (ER): The endemicity rate of filariasis in the study population was found to be $44.76 \%$ with $22.67 \%$ microfilariaemia and $22.09 \%$ crude disease rate (CDR) (Table 2).

Table 2. Total endemicity rate of filariasis.

\begin{tabular}{|l|l|l|l|l|}
\hline $\begin{array}{l}\text { T o t a I } \\
\text { samples }\end{array}$ & mf (\%) & CDR (\%) & ( mf+CDR) (\%) & ER (\%) \\
\hline 516 & $79(15.31)$ & $114(22.09)$ & $38(07.36)$ & $231(44.76)$ \\
\hline
\end{tabular}

Sex-wise endemicity rate: Males showed the highest endemicity rate $(49.09 \%)$ than females $(41.55 \%)$ which was statistically insignificant $(x 2=2.9, P<0.05,3$ d.f.) (Figure 6$)$.

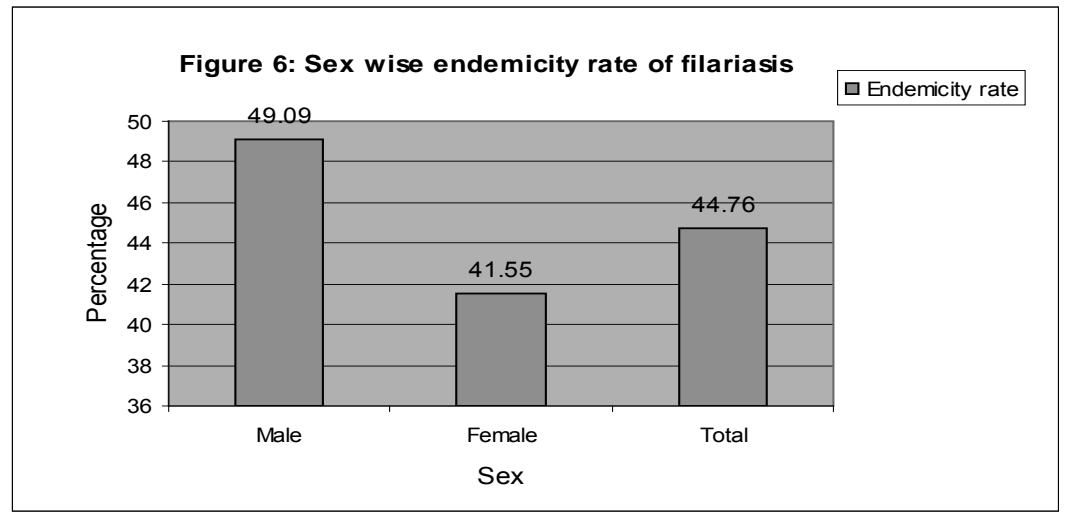

Age-wise Endemicity Rate: The overall study revealed the highest endemicity rate in the age group $51-60$ years $(68.75 \%)$ and the lowest in the age group $\leq 10$ years $(28.86 \%)$ (Figure 7 ). 


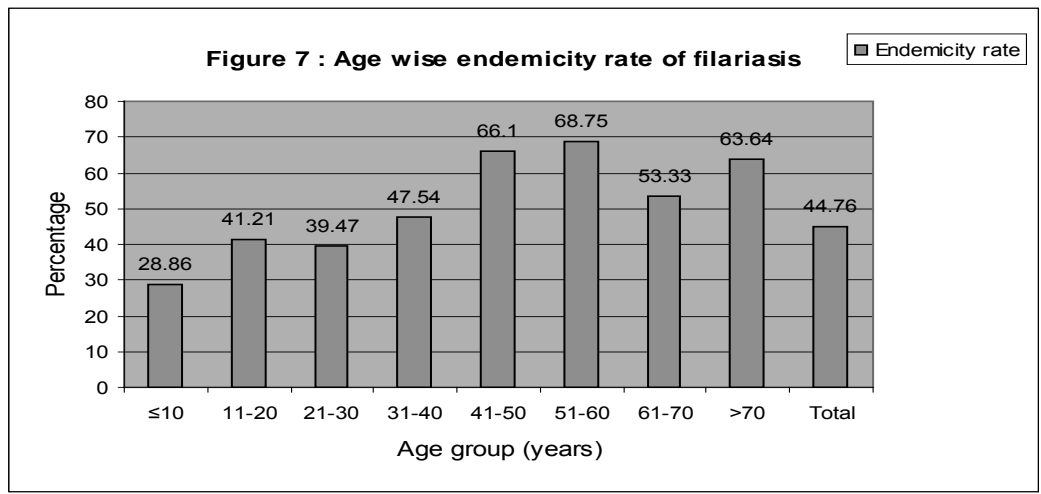

Prevalence of Microfilarial Parasites in Relation to the Use of Mosquito Nets

$20.86 \%$ of the mosquito net users and $23.71 \%$ of the non net users showed the infection (Table 3).

Table 3. Prevalence of microfilarial parasites in relation to the use of mosquito nets.

\begin{tabular}{|l|l|l|l|l|l|}
\hline \multirow{2}{*}{ SN } & \multirow{2}{*}{ Use of mosquito nets } & \multicolumn{2}{|l|}{ Total people } & \multicolumn{2}{l|}{ Positive samples } \\
\cline { 3 - 7 } & & No. & $\%$ & No. & $\%$ \\
\hline 1. & Yes & 187 & 36.24 & 39 & 20.86 \\
\hline 2. & No & 329 & 63.76 & 78 & 23.71 \\
\hline Total & & 516 & 100.00 & 117 & 22.67 \\
\hline
\end{tabular}

Distribution of Microfilarial Parasites in Relation to the Knowledge About Lymphatic filariasis

$25.95 \%$ of the respondents with the knowledge about the filariasis and $21.56 \%$ of the people without any knowledge about it were infected with the filarial parasites(Table 4).

Table 4. Distribution of microfilarial parasites in relation to the knowledge about lymphatic filariasis.

\begin{tabular}{|l|l|l|l|l|l|}
\hline \multirow{2}{*}{ SN } & \multirow{2}{*}{ Knowledge } & \multicolumn{2}{l|}{ Total people } & \multicolumn{2}{l|}{ Positive samples } \\
\cline { 3 - 6 } & status & No. & $\%$ & No. & $\%$ \\
\hline 1. & Yes & 131 & 25.39 & 34 & 25.95 \\
\hline 2. & No & 385 & 74.61 & 83 & 21.56 \\
\hline Total & & 516 & 100 & 117 & 22.67 \\
\hline
\end{tabular}


Lymphatic filariasis has been estimated to be endemic in some 80 countries including 120 million people (WHO 2000). It has global distribution with serious endemicity in Asia and Africa. Filariasis has been known to be endemic in Nepal since a long time (EDCD 2005) and reported from different areas. The present study revealed the endemicity rate of $44.76 \%$ with overall microfilariaemia of $22.67 \%$ and crude disease rate of $22.09 \%$. Among 117 positive microfilarial cases, $54 / 220(24.54 \%)$ were of males and $63 / 296(21.28 \%)$ were of females. Males and females were infected in the ratio of 1.2:1. This is supported by Weerasooriya et al. (2001) Srilanka. This may be due to the fact that during the summer, which is the optimum breeding season of mosquito, males usually sleep outdoor without using net and hence are more exposed to mosquito biting and also their usual dressing style, only vest and pant lead maximum biting by mosquito in the exposed parts of the body. While females are less susceptible to mosquito biting because they sleep indoor with their children using mosquito nets hence, are less exposed to mosquito biting.

All the age groups are susceptible to filariasis. The present study reveals high infection rate in the age group $>70$ years i.e. $36.36 \%$ while least in the age group $\leq 10$ years i.e. $12.37 \%$. The highest prevalence of microfilariae in the age group $>70$ years may be because of high exposure towards outer environment, lack of awareness and carelessness towards using nets, about health and hygiene and also because of the age factor while the lowest prevalence in the age group below 10 years is because of their indoor sleeping habit using mosquito nets. Age wise distribution of filariasis is equivalent to the length of the exposure; this is also supported by WHO (2001). According to Witt and Ottesen (2001) although LF is first acquired in childhood, clinical features occur only after puberty and hence increase with age. Massaya et al. (2000) also supported that clinical manifestation and microfilaria prevalence increases with age.

The maximum prevalence rate was reported in the children with education up to lower secondary level i.e. $31.25 \%$ (15/48). Since collected samples consisted of more illiterate people (because the illiteracy rate was high), many positive cases were recorded in them i.e. $21.43 \%(75 / 196)$. Similar type of result has also been obtained by Chhetri (2005). Regarding the knowledge, most of the people i.e. $74.61 \%$ were still unaware about the disease and only $25.39 \%$ knew about it.

During the field survey, it was found that the environmental condition and sanitation around the house play a major role to spread filariasis. Similar result had been obtained by Chhetri (2005) and Jha (2003). In the surveyed area, it was observed that the surrounding environment of most of the households were dirty. People also domesticated animals near their settlements. They either use their own house as the cattle shed or construct it close to their residence. Also each and every household has a large pit dug for accumulating the cattle dung for using as manure. During rainy seasons, these pits get filled up with water, which become an important site for mosquito breeding. The presence of bushy area around the house also supports the growth of mosquito. Not only this, people were found to work in the early morning and evening time which is suitable time for mosquito biting. Such conditions increase the chance of mosquito breeding and biting hence increasing the spread of vector borne diseases. These are the major risk factors for acquiring the vector borne disease filariasis.

By performing the survey on filariasis in the Salyantar VDC of Dhading district, it can be 
concluded that illiteracy which is responsible for lack of awareness towards the vector borne diseases, poor sanitary conditions around the house, carelessness towards health and hygiene and also carelessness towards the use of mosquito nets are the major contributing factors for the epidemicity of filariasis. Hence extensive study should be undertaken to determine the epidemiological and etiological factors that cause the high prevalence of filarial parasites. Along with this, mass drug administration, its regular monitoring and awareness programs seem the essential factors needed to be put forwarded for having control in the spread of filariasis.

\section{ACKNOWLEDGEMENTS}

We sincerely thank "PARASED" (Parasitological Research and Socio-Environmental Development, Nepal) for involving us in the project which was sponsored by Filariasis Elimination Program, EDCD (Epidemiological Division for Disease Control), Teku, Kathmandu. We would also like to thank all the local people and the health workers of Salyantar VDC for their help and contribution during the field work.

\section{REFERENCES}

Bista, M.B., M.K. Banerjee, G.D. Thakur and S.B. Shrestha,1995-1999. Lymphatic filariasis: Review of literature and epidemiological analysis of the situation in Nepal. Annual Report, Epidemiological and Disease Control Division, Department of Health Services, Ministry of Health.

Chhetri, B.R., 2005. An epidemiological sentinel survey of lymphatic filariasis (microfilaria) in Bishnupura VDC, Rupandehi district of Nepal. MSc. Dissertation Submitted to Central Department of Zoology, Tribhuvan University, Kirtipur, Kathmandu.

EDCD, 2005. Review of literature and epidemiological analysis of the situation in Nepal. Annual Report, Epidemilogical and Disease Control Division, Department of Health Services, Ministry of Health.

Ghimire, P., D.R. Bhatta, G.D.,Thakur, K. Parajuli, N.P. Yadav and R.K. Pokharel, 2002. Prevalence of lymphatic filariasis in an endemic district of Nepal. Journal of Tropical Medicine and Parasitology, 26:57-61.

Jha, S.C., 2003. An epidemiological study of microfilarial infection in eight districts of Nepal. MSc. Dissertation Submitted to Central Department of Zoology, Tribhuvan University, Kirtipur, Kathmandu.

Jung, R.K.,1973. A brief study on the epidemiology of filariasis in Nepal. Journal of Nepal Medical Association, 11:155-168.

Manandhar, R., 2001. Epidemiological study of microfilariasis in 3 different geographical regions of Nepal. Journal by Department of Micor, Institute of Medicine, 112:1-10.

Massaya, J.J., F.M. Salum and Z.X. Sarael, 2000. Clinical and parasitological aspects of bancroftian filariasis in Hale, Northern Tanzania. Central Africa Journal of Medicine, 46:236-241.

Pradhan, S.P., I. Shrestha, N. Palikhey and P.R. Uprety,1997. Epidemiological study of lymphatic filariasis in Gokarna VDC of Kathmandu valley during August and September 1997. Journal of Nepal Health Research Council, 2:13. 
Sherchand, J.B., V. Obsomer, G.D. Thakur and M. Hommel, 2003. Mapping of lymphatic filariasis in Nepal. Electronic Journal, 2(7):16-26.

Thakur, G.D., 2000. Epidemiological situation of lymphatic filariasis in Nepal. Report Submitted to Ministry of Health, Vector Borne Disease Research and Training Centre, Hetauda.

Weerasoriyia, I.M., M.Z. Ishlam, X.G. Quiu, Y. Fujimaki and E. Kimura, 2001. Prevalence and levels of filarial specific urinary $\mathrm{I}_{\mathrm{g}} \mathrm{G} 4$ among children Isess than five years of age and the association of antibody positivity between children and then mothers. American Journal and Hygiene, 68 (4):465-468.

WHO, 1997. Lymphatic filariasis. Thirteen Programme Report, World Health Organization, 75-85.

WHO, 2000. Eliminate filariasis attack poverty. CDS/SPE. World Health Organization, 5: 1-35.

WHO, 2001. Regional strategic plan for elimination of lymphatic filariasis. SEA/FIL. World Health Oranization, 28:1-6.

Witt, C. and E.A. Ottesen, 2001. Lymphatic filariasis: An infection in childhood. Tropical Medicine and International Health, 6(8):582-606.

\section{AUTHOR'S ADDRESS}

Reena Byanju ${ }^{1}$

Patan Multiple Campus, Tribhuvan University, Lalitpur, Nepal

(email: reenabyanju1@gmail.com)

\section{Ranjana Gupta ${ }^{2}$}

Central Department of Zoology, Tribhuvan University, Kirtipur, Kathmandu, Nepal 